\title{
Interaction effects between total energy and macronutrient intakes and angiotensin-converting enzyme $1(A C E)$ I/D polymorphism on adiposity-related phenotypes in toddlers and preschoolers: the Growth, Exercise and Nutrition Epidemiological Study in preSchoolers (GENESIS)
}

Georgia Kourlaba ${ }^{1}$, Yannis P. Pitsiladis ${ }^{2}$, Vasiliki Lagou ${ }^{2}$, Evangelia Grammatikaki ${ }^{1}$, Colin N. Moran $^{2}$, Katerina Kondaki ${ }^{1}$, Eleytheria Roma-Giannikou ${ }^{3}$ and Yannis Manios ${ }^{1} *$

${ }^{1}$ Department of Nutrition and Dietetics, Harokopio University of Athens, 70 El. Venizelou Ave, Kallithea 17671, Athens, Greece

${ }^{2}$ Institute of Diet, Exercise and Lifestyle (IDEAL), Faculty of Biomedical and Life Sciences, University of Glasgow, Glasgow G12 8QQ, UK

${ }^{3}$ First Department of Pediatrics, Athens University, Ag. Sophia Children's Hospital, Thivon and Levadias, Athens 11527, Greece

(Received 6 August 2007 - Revised 18 March 2008 - Accepted 19 March 2008 - First published online 15 May 2008)

\begin{abstract}
The aim of the present study was to investigate the interaction between the angiotensin-converting enzyme 1 (ACE) I/D polymorphism and energy and macronutrient intakes on adiposity-related phenotypes among toddlers and preschoolers. A representative sample of 2374 Greek children aged 1 to 5 years old was examined (Growth, Exercise and Nutrition Epidemiological Study in preSchoolers (GENESIS)). Dietary and anthropometric (i.e. BMI, waist circumference (WC)) assessments were carried out using standard procedures. DNA samples were obtained from 2102 children and were genotyped for the ACE I/D polymorphism. Among the entire population, $17 \%$ were 'at risk of overweight' and a similar percentage were 'overweight'. The frequencies of the II, ID and DD genotypes were 16, 46 and $38 \%$, respectively. Significant interactions were found between the $A C E$ I/D polymorphism and total energy intake on WC $(P=0.004$ for interaction) and the $A C E$ I/D polymorphism and protein intake on BMI and being overweight $(P<0.05$ for interaction). Furthermore, it was found that the ACE I/D polymorphism may modify the effect of fat intake on WC and BMI, but this interaction disappeared after adjustment for additional potential confounders. Stratified analyses revealed that total energy is correlated with WC and protein intake is associated with BMI and being overweight only among carriers of the D-allele (i.e. DD or ID genotypes). These results suggest that the ACE I/D polymorphism may act as a modifying factor in the response of adiposity-related phenotypes to diet.
\end{abstract}

Gene-nutrient interaction: Protein intake: Carbohydrate intake: Fat intake

Childhood overweight and obesity rates are increasing worldwide and have reached epidemic proportions in many developed countries ${ }^{(1-3)}$. This increase has been proposed to be due to changes in environmental factors such as an increase in the fat content of the diet and a decrease in physical activity $^{(4-6)}$. However, it is also evident that genetic factors play an important role in mediating the effect of environmental factors on obesity ${ }^{(7)}$ and it is estimated that $40-70 \%$ of the inter-individual variation in adiposity is due to environment-gene interactions ${ }^{(8)}$.

Genotype-environment interactions arise when the response of a phenotype (for example, body weight) to environmental changes (for example, dietary intervention) is modulated by the genotype of the individual. Determining these interaction effects for obesity-related phenotypes is important because it will facilitate the identification of individuals at risk of obesity, as well as those likely to be resistant to dietary interventions and hence requiring more drastic or better-adjusted dietary prescription.

The most recent obesity gene map indicates that there are more than 100 genes that have the potential to influence obesity ${ }^{(9)}$. The most widely studied genes are those implicated in the regulation of adipose tissue metabolism and those controlling energy intake and expenditure. One candidate gene is the angiotensin-converting enzyme $1(A C E)$ gene. This is a key component of the renin-angiotensin system that converts angiotensin I to II (a vasoconstrictor) ${ }^{(10)}$, as well as hydrolysing bradykinin (a vasodilator) and other active oligopeptides $^{(11)}$. Several components of the renin-angiotensin system have been detected in adipose tissue ${ }^{(12)}$ and the local renin-angiotensin system may be involved in the regulation of adipose tissue physiology and possibly in the pathophysiology of obesity and obesity-associated hypertension, since it has been shown that angiotensin II increases lipogenesis ${ }^{(13)}$.

Abbreviations: $A C E$, angiotensin-converting enzyme 1; GENESIS, Growth, Exercise and Nutrition Epidemiological Study in preSchoolers; L-VPA, light to vigorous physical activities.

* Corresponding author: Assistant Professor Yannis Manios, fax +30 210 9549141, email manios@hua.gr 
More than 100 polymorphisms have been reported in the $A C E$ gene, with the $A C E$ insertion/deletion (I/D) polymorphism being repeatedly found to be associated with obesity-related phenotypes ${ }^{(14-16)}$. Given its position in an intron, it is unlikely that the $\mathrm{I} / \mathrm{D}$ polymorphism is a functional variant and more likely that these associations are mediated through linkage disequilibrium with a neighbouring functional variant. However, the I/D polymorphism associates with $A C E$ activity and remains an easily testable proxy for any functional polymorphism. The I-allele is associated with lower, and the D-allele with higher, circulating ACE activity. Recently, Moran et al. examined the effect of an interaction between the $A C E$ I/D polymorphism and lifestyle on adiposity in Greek adolescents ${ }^{(16)}$. To our knowledge, there are no data regarding the potential interaction effect between the $A C E$ I/D polymorphism and diet on adiposity-related phenotypes. Therefore, the aim of the present study was to assess whether the $A C E$ I/D polymorphism modifies any effect of diet (i.e. total energy, fat, protein and carbohydrate intake) on obesity-related phenotypes among toddlers and preschoolers.

\section{Methods}

\section{Sampling}

The design and rationale of the "Growth, Exercise and Nutrition Epidemiological Study in preSchoolers' (GENESIS) have been published previously ${ }^{(17)}$. Briefly, between April 2003 and July 2004, 2518 children, aged 1-5 years were recruited in the study from a representative sample of randomly selected public and private nurseries as well as day-care centres within municipalities in five counties of Greece. All nurseries invited to participate responded positively. Each parent having a child in these nurseries received an extended letter explaining the aims of the study and a consent form. Those parents that agreed to participate in the study had to sign the consent form and provide their contact details. From the total number of positive responses (response rate $75 \%$ ), complete data became available for 2374 children with participation rate varying from 54 to $95 \%$, reaching the highest rates in rural areas and the lowest in urban areas. Approval to conduct the study was granted by the Ethical Committee of Harokopio University and by all municipalities invited to participate in the study.

\section{Anthropometric measurements}

Body weight was recorded to the nearest $10 \mathrm{~g}$, recumbent length to the nearest $0.1 \mathrm{~cm}$ and standing height to the nearest $0 \cdot 1 \mathrm{~cm}$, as well as waist circumference (WC). Details about the measures used for performing the aforementioned measurements are presented elsewhere ${ }^{(17)}$. BMI was calculated as the ratio of weight $(\mathrm{kg})$ with height squared $\left(\mathrm{m}^{2}\right)$. The Nutstat module of EpiInfo ${ }^{(18)}$ was used to determine children's age and sex-specific percentiles for weight, length and BMI. The US Center for Disease Control age- and sex-specific growth charts and relative cut-off points were used for the definition of overweight ${ }^{(19)}$. Specifically, up to 24 months the weightfor-length growth chart was used to classify children $>95$ th percentile as 'overweight', while for children older than 24 months, the BMI-for-age chart was used to classify children $\geq 85$ th and $<95$ th percentile as 'at risk of overweight' and those $\geq 95$ th percentile as 'overweight'. Subsequently, we divided children into overweight (those being 'at risk of overweight' or 'overweight') and normal weight (those with normal weight or underweight). Finally, paternal and maternal BMI were calculated from self-reported height and weight.

\section{Dietary assessment}

Dietary intake data were obtained for two consecutive weekdays and one weekend day using a combination of techniques comprising weighed food records (during nursery hours) and $24 \mathrm{~h}$ recall or food diaries (outside nurseries, under parents' or guardians' supervision). More specifically, during the two weekdays, and while the child was at the nursery, a team member weighed and recorded all foods consumed by each child. Information on the food consumed outside the nursery was obtained during a prearranged meeting with the parent or guardian the following day. During the interview each parent or guardian was familiarised with portion sizes and the relevant procedures required to successfully complete a food record at home on the forthcoming weekend day, most preferably Sunday. Parents were advised to return the food diaries at the nursery on Monday mornings, where a team member received and checked the records for any errors. Food intake data were analysed using the Nutritionist V diet analysis software (First Databank, San Bruno, CA, USA), which was extensively amended to include traditional Greek foods and recipes ${ }^{(20,21)}$.

\section{Physical activity assessment}

Using a valid, structured questionnaire, information regarding children's physical activity was obtained by parents during scheduled interviews at the nurseries ${ }^{(17)}$. Parents were asked to provide information on their child's participation in outdoor organised or non-organised physical activities while a research team member recorded this information on this proxy questionnaire. Emphasis was placed on 'light to vigorous physical activities' (L-VPA) with intensity higher than 4 metabolic equivalents. More information on the type of activities comprising L-VPA is presented elsewhere ${ }^{(17)}$.

\section{Data obtained by parents and birth certificates}

A structured interview was conducted with both parents, in order to collect additional information regarding: (a) parental educational level; (b) maternal medical history of gestational diabetes; (c) maternal active and passive smoking patterns during pregnancy; (d) mother's age at birth; (e) parity (firstborn $v$. not first-born child); (f) children's feeding patterns from birth to 6 months of age (i.e. breast-feeding, use of formula and age when formula was first initiated). Based on the collected information and on the criteria provided by the WHO for the definition of breast-feeding the following three categories were created: exclusive breast-feeding, exclusive formula feeding and mixed feeding with concurrent use of breast milk and formula.

Furthermore, parents were asked to bring with them their child's birth certificate and medical record from which the birth weight, child's weight and recumbent length at 
6 months of age were recorded. By asking mothers about the date of their last menstrual period gestational age was obtained. Weight gain during the first 6 months of life was defined as the difference in weight-for-length $z$-scores from birth to 6 months of age. The following ranges in the observed $z$-score differences were used to categorise weight gain of children as 'poor' $(<-1$ $z$-score difference), 'average' ( -1 to $+1 z$-score difference) or 'rapid' $(>+1 \quad z$-score difference). This categorisation allows both comparisons of fast-growing children against all others as well as dose-response examination.

\section{DNA extraction}

Buccal cell samples were obtained non-invasively by cytology brush (Medical Packaging Corporation, Camarillo, CA, USA) from 2374 subjects (1218 males and 1156 females) according to the manufacturer's recommendations and stored in Eppendorf tubes containing cell lysis solution (0.1 M-EDTA, $1 \%$ SDS, $0 \cdot 1 \mathrm{M}$-2-amino-2-hydroxymethyl-propane-1,3-diol-HCl, pH 7.6). Genomic DNA was extracted using Nucleospin ${ }^{\circledR}$ Tissue columns and a 96 Tissue Purification Kit (Clontech, Inc., Mountain View, CA, USA). After purification, DNA was stored in Thermofast rigid semi-skirted ninety-six-well plates (ABgene, Epsom, Surrey, UK) at $-20^{\circ} \mathrm{C}^{(15)}$.

\section{Genotyping}

DNA amplification was carried out for the $A C E$ I/D polymorphism. Genotypes were determined as previously described $^{(16)}$. Briefly, a three-primer system was used including a forward primer recognising the deletion (D) sequence, a forward primer specific for the insertion (I) sequence and a common reverse primer. PCR reactions were performed in a final volume of $25 \mu \mathrm{l}$ and the presence of the I- and D-allele resulted in $252 \mathrm{bp}$ and $197 \mathrm{bp}$ products respectively.

\section{Statistical analysis}

The Shapiro-Wilk test was used to evaluate the normality of continuous variables (i.e. BMI, WC, total energy and macronutrient intakes). Although the test showed that BMI and WC are not normally distributed, the histogram of these characteristics showed that their distribution approximates well the normal distribution. Therefore, no transformation was performed. Continuous variables are presented as mean values and standard deviations, and categorical variables are summarised as absolute and relative (\%) frequencies. Correlations between BMI, WC and total energy and macronutrient intakes were evaluated by the Pearson's correlation coefficient, while the associations between macronutrient and total energy intakes and the binary variable indicating normal-weight and overweight children were evaluated through the Student's $t$ test. Associations between genotype distributions and other categorical variables were tested by the use of contingency tables and the calculation of $\chi^{2}$ tests without the correction of continuity. Comparisons between continuous variables and three genotypes of the $A C E$ I/D polymorphism (i.e. II, ID, DD) were evaluated using one-way ANOVA after testing for equality of variances (homoscedacity). However, due to multiple significance comparisons, we used the Bonferroni correction in order to account for the increase in type I error.

Multiple logistic regression analysis was applied to evaluate the associations between being overweight ('overweight' or 'at risk of overweight' $v$. normal weight) and the $A C E \mathrm{I} / \mathrm{D}$ polymorphism as well as total energy intake, while multiple linear regression was performed to evaluate the associations between BMI, WC and the $A C E$ I/D polymorphism as well as total energy intake. To explore whether the $A C E$ I/D polymorphism modifies the effect of total energy intake on obesity-related phenotypes, two interaction terms were included in the models. These terms comprised of the product of two dichotomous $A C E$ I/D genotype variables (dummy variables) with total energy intake. The test for interaction was performed comparing the likelihood of the model without interaction terms with the likelihood of the model including interaction terms, through the likelihood ratio test. Similar analyses were performed using macronutrient intakes (i.e. protein, fat and carbohydrate intakes, separately) instead of total energy intake. When interaction terms were statistically significant (i.e. total energy intake $\times A C E \mathrm{I} / \mathrm{D}$, fat intake $\times A C E$ $\mathrm{I} / \mathrm{D}$ and protein intake $\times A C E \mathrm{I} / \mathrm{D})$, stratified analysis by $A C E$ genotype was performed. As such, we evaluated the effect of total energy intake, protein and fat intake, separately, on obesity-related phenotypes after controlling for potential (i.e. child's age, sex, maternal age at birth, parity, postnatal feeding practice, gestational diabetes, maternal educational status (years), maternal smoking during pregnancy, birth weight, weight gain in the first 6 months, parental BMI, time spent on L-VPA). Appropriate tests for goodness of fit (i.e. Hosmer-Lemeshow test for logistic regression and plots of jack-knife residuals against fitted values for linear regression) were applied to final models. A probability value of $5 \%$ was considered statistically significant. All statistical calculations were performed using SPSS version 14.0 software (SPSS Inc., Chicago, IL, USA).

\section{Results}

\section{Characteristics of the participants}

Obesity-related measures and dietary characteristics of participants by sex as well as for the entire population are presented in Table 1. No difference was observed in obesity-related phenotypes (i.e. BMI, WC, weight status) between sexes, while the total energy and macronutrient intakes were higher in boys compared with girls. Among the entire population, $17 \%$ were 'at risk of overweight' and $17.6 \%$ were 'overweight'.

\section{Association between diet and obesity-related phenotypes}

Univariate analysis revealed that the total energy intake as well as the total fat and saturated fat intake of overweight children was higher compared with normal-weight children, while the former consumed lower quantities of carbohydrate compared with the latter (Table 2). After controlling for potential confounders (i.e. age of child, sex, maternal age at birth, parity, postnatal feeding practice, gestational diabetes, maternal educational status, maternal smoking during pregnancy, birth weight, weight gain in the first 6 months, parental BMI, time spent on L-VPA) through multiple logistic regression, total energy, 
Table 1. Obesity-related measures and dietary characteristics of toddlers and preschoolers in the Growth, Exercise and Nutrition Epidemiological Study in preSchoolers by sex and for all participants

(Mean values and standard deviations)

\begin{tabular}{|c|c|c|c|c|c|c|}
\hline & \multicolumn{2}{|c|}{ Boys ( $n$ 1215) } & \multicolumn{2}{|c|}{ Girls ( $n$ 1131) } & \multicolumn{2}{|c|}{ All $(n$ 2346) } \\
\hline & Mean & SD & Mean & SD & Mean & SD \\
\hline Age of children (months) & 41.5 & $12 \cdot 0$ & 41.7 & $12 \cdot 0$ & 41.5 & 11.8 \\
\hline BMI of children $\left(\mathrm{kg} / \mathrm{m}^{2}\right)$ & $16 \cdot 3$ & 1.6 & $16 \cdot 3$ & 1.6 & $16 \cdot 3$ & 1.6 \\
\hline \multicolumn{7}{|l|}{ Children's weight status $†$} \\
\hline Normal weight (\%) & \multirow{2}{*}{\multicolumn{2}{|c|}{$\begin{array}{l}66 \\
34\end{array}$}} & \multirow{2}{*}{\multicolumn{2}{|c|}{$\begin{array}{l}65 \\
35\end{array}$}} & \multicolumn{2}{|c|}{65} \\
\hline At risk of overweight or overweight (\%) & & & & & \multicolumn{2}{|c|}{35} \\
\hline Waist circumference of child $(\mathrm{cm})$ & $51 \cdot 2$ & 4.2 & $51 \cdot 3$ & 4.7 & $51 \cdot 3$ & 4.5 \\
\hline Birth weight $(\mathrm{kg})$ & 3.4 & 0.5 & $3 \cdot 2^{*}$ & 0.5 & $3 \cdot 3$ & 0.5 \\
\hline Total energy intake $(\mathrm{kJ} / \mathrm{d})$ & 5933.0 & $1318 \cdot 0$ & $5627 \cdot 0^{*}$ & $1218 \cdot 0$ & $5820 \cdot 0$ & $1326 \cdot 0$ \\
\hline Protein intake $(\mathrm{g} / \mathrm{d})$ & $58 \cdot 6$ & $15 \cdot 5$ & $55 \cdot 4^{*}$ & $14 \cdot 6$ & $16 \cdot 5$ & $2 \cdot 6$ \\
\hline Total fat intake $(\mathrm{g} / \mathrm{d})$ & $63 \cdot 2$ & $17 \cdot 8$ & $59 \cdot 9^{*}$ & $16 \cdot 5$ & $40 \cdot 0$ & 5.5 \\
\hline Saturated fat intake $(\mathrm{g} / \mathrm{d})$ & $26 \cdot 0$ & 8.8 & $24 \cdot 5^{*}$ & 7.9 & $25 \cdot 3$ & 8.4 \\
\hline Monounsaturated fat intake $(\mathrm{g} / \mathrm{d})$ & $26 \cdot 0$ & 8.4 & $24 \cdot 7^{*}$ & 7.9 & $25 \cdot 4$ & $8 \cdot 2$ \\
\hline Polyunsaturated fat intake $(\mathrm{g} / \mathrm{d})$ & $6 \cdot 7$ & $2 \cdot 4$ & $6 \cdot 4^{*}$ & $2 \cdot 4$ & 6.5 & 2.4 \\
\hline Total carbohydrate intake $(\mathrm{g} / \mathrm{d})$ & $161 \cdot 3$ & 40.8 & $153 \cdot 2^{*}$ & 37.9 & $45 \cdot 6$ & $6 \cdot 7$ \\
\hline Simple carbohydrate intake $(\mathrm{g} / \mathrm{d})$ & 41.8 & $21 \cdot 7$ & $38 \cdot 8^{*}$ & $19 \cdot 1$ & $40 \cdot 4$ & 20.5 \\
\hline
\end{tabular}

* Mean value was significantly different from that of the boys $(P<0.05)$

†Data are presented as relative (\%) frequencies.

fat, saturated fat and carbohydrate intakes remained significant factors for being overweight (data not shown). Moreover, we found that total energy intake and all macronutrient intakes, with the exception of protein and simple carbohydrate intake, were significantly correlated with WC, while only total energy intake was significantly correlated with BMI (Table 2). After adjustment for the aforementioned confounders, only total energy intake was positively associated with BMI and WC $(P<0 \cdot 01$; data not shown).

Distribution of angiotensin-converting enzyme 1 (ACE) I/D polymorphism and its association with obesity-related phenotypes

Genotyping for the ACE I/D polymorphism was successful in 2033 individuals. The population was found to be in HardyWeinberg equilibrium at this locus $(P=0 \cdot 199)$ and the overall allele frequencies were $f_{(\mathrm{I})}=0.39$ and $f_{(\mathrm{D})}=0.61$.
The genotype frequency was 38,46 and $16 \%$ for DD, DI and II, respectively. There were no differences in genotype frequencies between boys and girls $(P=0 \cdot 694)^{(15)}$. No difference was observed in macronutrient intakes among the three genotypes as well as in BMI and WC. Although the present results did not reach statistical significance, the prevalence of overweight was higher among children with the II genotype (37\%) compared with those with DD (32\%) and those with ID (32\%; $P=0 \cdot 166)$. Similar results were observed after stratified analysis by sex.

\section{Obesity-related phenotypes, angiotensin-converting enzyme 1 (ACE) I/D polymorphism and diet}

In order to evaluate whether the $A C E$ genotype modifies the effect of total energy intake on adiposity-related phenotypes, multiple logistic (for binary variable as phenotype) and linear regression (for BMI and WC as phenotype) models

Table 2. Relationships between macronutrient intakes and obesity-related phenotypes among toddlers and preschoolers in the Growth, Exercise and Nutrition Epidemiological Study in preSchoolers: results from univariate analysis (Mean values and standard deviations)

\begin{tabular}{|c|c|c|c|c|c|c|}
\hline & \multicolumn{4}{|c|}{ Being overweight $†$} & \multirow[b]{3}{*}{ BMI } & \multirow[b]{3}{*}{ WC } \\
\hline & \multicolumn{2}{|c|}{ Normal } & \multicolumn{2}{|c|}{ Overweight } & & \\
\hline & Mean & SD & Mean & SD & & \\
\hline Total energy intake $(\mathrm{kJ} / \mathrm{d})$ & 5753 & 1226 & $5950^{*}$ & 1372 & $0.092^{*}$ & $0.214^{*}$ \\
\hline Total fat intake (\% total energy intake) & $39 \cdot 8$ & $5 \cdot 6$ & $40 \cdot 4^{*}$ & $5 \cdot 2$ & 0.043 & $0 \cdot 120^{*}$ \\
\hline Saturated fat intake (\% total energy intake) & $16 \cdot 3$ & $3 \cdot 6$ & $16 \cdot 7^{\star}$ & 3.6 & 0.052 & $0.086^{*}$ \\
\hline Monounsaturated fat intake (\% total energy intake) & $16 \cdot 4$ & $3 \cdot 4$ & $16 \cdot 6$ & $3 \cdot 2$ & 0.003 & $0.124^{*}$ \\
\hline Polyunsaturated fat intake (\% total energy intake) & $4 \cdot 2$ & $1 \cdot 2$ & $4 \cdot 3$ & $1 \cdot 2$ & -0.023 & $0.091^{*}$ \\
\hline Protein intake (\% total energy intake) & $16 \cdot 5$ & $2 \cdot 6$ & $16 \cdot 6$ & $2 \cdot 5$ & 0.004 & -0.020 \\
\hline Total carbohydrate intake ( $\%$ total energy intake) & $45 \cdot 8$ & $6 \cdot 8$ & $44 \cdot 9^{*}$ & $6 \cdot 2$ & -0.046 & $-0.087^{\star}$ \\
\hline Simple carbohydrate intake (\% total energy intake) & $11 \cdot 8$ & $5 \cdot 4$ & $11 \cdot 3$ & $4 \cdot 8$ & -0.065 & 0.005 \\
\hline
\end{tabular}

WC, waist circumference.

${ }^{*} P<0.05$

†The comparison of mean values between the two groups (i.e. normal and overweight) was performed by using the Student's $t$ test. $\ddagger$ Pearson correlations. 
including total energy intake, $A C E$ genotype and their interaction terms were applied (model 1; Table 3 ). In these models, age and sex of children were also included as potential confounders. It was found that the $A C E$ I/D polymorphism modifies significantly the effect of total energy intake on WC. After adjustment for additional potential confounders (i.e. maternal age at birth, parity, postnatal feeding practice, gestational diabetes, maternal educational status, maternal smoking during pregnancy, birth weight, weight gain in the first 6 months, parental BMI, time spent on L-VPA), the interaction effect on WC remained significant $(P=0 \cdot 05)$ (data not shown).

Similar analyses were performed for the evaluation of the potential interaction between several macronutrient intakes (i.e. total fat, protein and carbohydrate intake) and $A C E \mathrm{I} / \mathrm{D}$ genotype (models 2, 3 and 4 , respectively) (Table 3 ). The interaction between the $A C E \mathrm{I} / \mathrm{D}$ polymorphism and protein intake was statistically significant for all obesity-related phenotypes, after adjustment only for age and sex. However, after controlling for additional potential confounders, the interaction effect remained significant only on BMI and being overweight. No statistically significant interaction was observed between carbohydrate intake and the $A C E \mathrm{I} / \mathrm{D}$ polymorphism. Moreover, it was revealed that the $A C E \mathrm{I} / \mathrm{D}$ polymorphism marginally modifies the effect of fat intake on WC and BMI, but this disappeared after adjustment for additional potential confounders, while no interaction between the $A C E$ I/D polymorphism and saturated fat intake was observed (data not shown for saturated fat intake).

When interaction terms were significant $(P<0.05$; likelihood ratio test) or marginally significant $(P<0 \cdot 1$; likelihood ratio test) for at least one obesity-related phenotype after adjustment for potential confounders, we performed stratified analysis by $A C E$ genotype, in order to explore the effect of diet on obesity-related phenotypes in each $A C E$ genotype. We subsequently applied stratified analysis for total energy, protein and total fat intake and found that total energy intake was positively associated with WC in carriers of the D allele (DD or ID genotypes; Table 4). Specifically, we found that a $418.4 \mathrm{~kJ}(100 \mathrm{kcal})$ increase in total energy intake was associated with $0 \cdot 1$ and $0 \cdot 3 \mathrm{~cm}$ increases in WC among children with the DD and ID genotypes, respectively (Table 4). Moreover, protein intake was found to be positively associated with the likelihood of being overweight and with BMI (marginally) among the DD homozygotes. In particular, a $1 \%$ total energy intake increment in protein intake is associated with $9 \%$ higher odds of being overweight $v$. normal and with a $0.04 \mathrm{~kg} / \mathrm{m}^{2}$ increase in BMI (Table 4).

\section{Discussion}

Obesity prevalence has increased enormously in the last decades both in children and adults. This rise has reached

Table 3. Results from logistic and linear regression models evaluating the effect of interaction between angiotensin-converting enzyme 1 ( $A C E$ ) I/D polymorphism and diet on adiposity-related phenotypes in toddlers and preschoolers (Growth, Exercise and Nutrition Epidemiological Study in preSchoolers)†

(Odds ratios or $\beta$ coefficients and $95 \%$ confidence intervals)

\begin{tabular}{|c|c|c|c|c|c|c|c|c|c|}
\hline & \multicolumn{3}{|c|}{ Being overweight } & \multicolumn{3}{|c|}{ BMI } & \multicolumn{3}{|c|}{ Waist circumference } \\
\hline & OR & $95 \% \mathrm{Cl}$ & $P$ & $\beta$ & $95 \% \mathrm{Cl}$ & $P$ & $\beta$ & $95 \% \mathrm{Cl}$ & $P$ \\
\hline \multicolumn{10}{|l|}{ Model 1} \\
\hline \multicolumn{10}{|l|}{$A C E \mathrm{l} / \mathrm{D}$ polymorphism } \\
\hline DD & \multicolumn{2}{|c|}{ Reference group } & - & \multicolumn{2}{|c|}{ Reference group } & - & \multicolumn{2}{|c|}{ Reference group } & - \\
\hline ID & 0.77 & $0 \cdot 27,2 \cdot 20$ & 0.625 & -0.74 & $-1.49,0.008$ & 0.053 & $-2 \cdot 68$ & $-4.50,-0.86$ & 0.004 \\
\hline II & 1.21 & $0.29,4.93$ & 0.787 & -0.04 & $-1.07,0.99$ & 0.937 & 0.42 & $-2.09,2.93$ & 0.741 \\
\hline Total energy intake & 1.00 & $0.99,1.00$ & 0.178 & $3 \times 10^{-4}$ & $-9 \times 10^{-5}, 7 \times 10^{-4}$ & 0.124 & $10^{-3}$ & $3 \times 10^{-4}, 0.002$ & 0.009 \\
\hline$A C E \times$ total energy intake ${ }^{*}$ & & - & 0.837 & & - & 0.094 & & - & 0.004 \\
\hline \multicolumn{10}{|l|}{ Model 2} \\
\hline \multicolumn{10}{|l|}{ ACE I/D polymorphism } \\
\hline DD & \multicolumn{2}{|c|}{ Reference group } & - & \multicolumn{2}{|c|}{ Reference group } & - & \multicolumn{2}{|c|}{ Reference group } & - \\
\hline ID & 0.40 & $0.07,2.1$ & 0.296 & -1.22 & $-2.37,-0.06$ & 0.038 & $-3 \cdot 23$ & $-6.08,0.38$ & 0.026 \\
\hline II & 2.42 & $0 \cdot 22,26 \cdot 20$ & 0.466 & -0.03 & $-1 \cdot 78,1.72$ & 0.973 & 0.38 & $-3.94,4.69$ & 0.863 \\
\hline Fat intake & 1.01 & $0.99,1.05$ & 0.216 & 0.002 & $-0.02,0.02$ & 0.794 & -0.003 & $-0.05,0.05$ & 0.893 \\
\hline$A C E \times$ fat intake* & & - & 0.339 & & - & 0.075 & & - & 0.050 \\
\hline \multicolumn{10}{|l|}{ Model 3} \\
\hline \multicolumn{10}{|l|}{$A C E \mathrm{I} / \mathrm{D}$ polymorphism } \\
\hline DD & \multicolumn{2}{|c|}{ Reference group } & - & \multicolumn{2}{|c|}{ Reference group } & - & \multicolumn{2}{|c|}{ Reference group } & - \\
\hline ID & 7.42 & $1.77,31.05$ & 0.006 & $1 \cdot 14$ & $0 \cdot 13,2 \cdot 18$ & 0.027 & 2.43 & $-0.09,4.95$ & 0.060 \\
\hline ॥ & 25.35 & $3.50,183.35$ & 0.001 & $2 \cdot 13$ & $0.68,3.58$ & 0.004 & $4 \cdot 10$ & $0.53,7.69$ & 0.025 \\
\hline Protein intake & 1.09 & $1 \cdot 03,1 \cdot 17$ & 0.005 & 0.05 & $0.003,0.09$ & 0.036 & 0.06 & $-0.05,0.17$ & 0.322 \\
\hline$A C E \times$ protein intake* & & - & 0.004 & & - & 0.013 & & - & 0.050 \\
\hline \multicolumn{10}{|l|}{ Model 4} \\
\hline \multicolumn{10}{|l|}{$A C E \mathrm{l} / \mathrm{D}$ polymorphism } \\
\hline DD & \multicolumn{2}{|c|}{ Reference group } & - & \multicolumn{2}{|c|}{ Reference group } & - & \multicolumn{2}{|c|}{ Reference group } & - \\
\hline ID & 0.68 & $0.14,3.27$ & 0.638 & 0.43 & $-0.66,1.52$ & 0.441 & 1.51 & $-1 \cdot 18,4 \cdot 21$ & 0.271 \\
\hline II & 0.18 & $0.02,1.64$ & 0.130 & -0.66 & $-2.29,0.97$ & 0.427 & -1.40 & $-5.43,2.62$ & 0.495 \\
\hline Carbohydrate intake & 0.96 & $0.94,0.99$ & 0.008 & -0.01 & $-0.03,0005$ & 0.153 & -0.007 & $-0.05,0.03$ & 0.750 \\
\hline$A C E \times$ carbohydrate intake ${ }^{\star}$ & & - & 0.187 & & - & 0.327 & & - & 0.197 \\
\hline
\end{tabular}

${ }^{*} P$ values for interaction terms have been obtained using the likelihood ratio test.

$\dagger$ Fat, protein and carbohydrate intakes were entered in the models as percentage of the total energy intake. All models were adjusted for sex and age of participants. 
the grade of 'epidemic phenomenon' in almost all regions of Europe, North America and Australia. It is extremely possible that excessive energy intake, the macronutrient composition of the diet, eating habits and/or low energy expenditure may have more influence on this phenomenon because the human genotype has not changed over the last few years. Moreover, there is strong evidence that the effect of diet on obesity-related phenotypes is partially determined by genetic factors. However, the lack of data regarding the nutrient-diet interaction among children is a major concern. Therefore, to our best knowledge, this is the first study to assess the relationship between the $A C E$ I/D polymorphism and macronutrient and energy intakes on obesity-related phenotypes in toddlers and preschoolers.

Our findings reveal that total energy intake, as well as protein intake, is positively associated with obesity-related phenotypes, but these associations are modified by the ACE I/D polymorphism. In particular, we observed that total energy intake is correlated with WC, and protein intake is associated with BMI (marginally) and being overweight only among carriers of the D allele (i.e. ID or DD genotypes). Moreover, it was observed that carbohydrate intake was negatively associated with the probability of being overweight independently of $A C E$ genotype (non-significant interaction between $A C E \mathrm{I} / \mathrm{D}$ polymorphism and carbohydrate intake).

Although no other studies have examined the possible interaction effect between diet and the $A C E$ I/D polymorphism, there are several studies that have explored whether overweight children eat more than their normal-weight counterparts and whether the diet composition may be related to weight gain in young individuals ${ }^{(22,23)}$. The results of the present study are partially consistent with the findings of some previous studies. In particular, Gillis et al. suggested that among children aged 4-16 years, there is a strong relationship between total energy consumed and juvenile adiposity ${ }^{(24)}$. Similarly, Berkey et al. reported that excessive energy intake in children aged 9-14 years is associated with an increase in $\mathrm{BMI}^{(25)}$. Moreover, in the GENESIS study, it was found that 'at risk of overweight' and 'overweight' toddlers and preschoolers consumed more total energy compared with their normal-weight counterparts and that the mean energy intakes of the participants exceeded their requirements ${ }^{(26)}$. Moreover, in good keeping with the findings of the present study, several previous cross-sectional studies found that obese children consumed a greater percentage of their energy intake in the form of fat and less in the form of carbohydrate compared with their lean counterparts ${ }^{(27-31)}$. However, other studies found negative or no association between energy intake and body $\mathrm{fat}^{(27-29,32-34)}$ as well as between the percentage of macronutrient intake and weight gain $^{(32,34-37)}$. These differences may be attributed to methodological errors, the use of inaccurate and imprecise techniques and characteristic psychological and dieting aspects that appear when obesity has already arisen. Moreover, the distribution of $A C E$ genotypes in the different study populations may play an important role in these discrepancies, since we revealed that the $A C E$ I/D polymorphism modifies the effect of total energy and macronutrient intake on obesity.

Furthermore, we found that protein intake is higher among 'at risk of being overweight' or 'overweight' preschoolers and toddlers compared with their normal-weight counterparts, 
while in a recently published work of the GENESIS, it has been reported that almost all toddlers and preschoolers had protein intakes more than estimated average requirement for protein ${ }^{(26)}$. In agreement with the present results, some investigators have proposed that protein intake during the first postnatal years is related to increased body size and adiposity. A possible explanation is that protein intake stimulates insulin-like growth factor-1 and insulin secretion, which promote fat storage and the proliferation of mature adipocytes ${ }^{(38-40)}$. Similar findings were found in a study on rats' in which it was found that the percentage of body fat in rats increased if they consumed an increasing proportion of $\operatorname{protein}^{(41)}$

Regarding our finding that the ACE I/D polymorphism may modulate the association between energy, macronutrient intakes and obesity-related phenotypes, no clear mechanism can be proposed. We found a positive association between total energy, protein intakes and obesity-related phenotypes among carriers of the $\mathrm{D}$ allele. A previous study has shown that the DD genotype is associated with higher circulating ACE levels than the other I/D genotypes ${ }^{(42)}$. ACE converts angiotensin I into angiotensin $\mathrm{II}^{(10)}$. Moreover, it has been shown that angiotensin II promotes adipocyte growth and differentiation and can inhibit lipolysis by reducing skeletal and adipose-tissue blood flow leading to increased fat storage in normal-weight and obese individuals ${ }^{(43)}$, as well as angiotensin II increasing lipid synthesis and storage in adipose cells in vitro ${ }^{(13)}$. Taking into account the aforementioned results we hypothesise that increased levels of angiotensin II observed in carriers of the D allele may be associated with alterations in macronutrient oxidation, thus resulting in fat storage and weight gain.

There are some limitations of the present study. Due to the cross-sectional design of the study, we cannot declare that the examined dietary components are predictors of paediatric obesity, but only that it is associated with an increased likelihood of being overweight. Moreover, the assessment of energy intake is, generally, questionable. Therefore, it is possible that there is a bias in the estimation of the association between diet and obesity. However, several aspects of the present study suggest enhanced reliability of the data (i.e. combination of weighed food records and $24 \mathrm{~h}$ recall or $3 \mathrm{~d}$ diary, highly qualified interviewers who checked the records for any misrecorded or missing information) ${ }^{(44)}$. Finally, we have not collected any data regarding the $A C E$ I/D polymorphism in parents.

In conclusion, it was revealed that the $A C E$ I/D polymorphism modifies the effect of total energy and protein intakes on obesity-related phenotypes in early childhood. In particular, we revealed that total energy intake is positively associated with WC and protein intake is positively correlated with BMI and being overweight only among children with the D allele of the $A C E$ gene. This means that increased protein and total energy intakes may be more burdensome factors for increased WC and increased BMI, respectively, among carriers of the $\mathrm{D}$ allele. These findings reinforce the importance of taking into account gene-nutrient interactions in the understanding of causal mechanisms of complex diseases such as obesity. Further research is required to confirm our findings and explore possible underlying mechanisms behind this interaction effect.

\section{Acknowledgements}

The authors would further like to thank Evdokia Oikonomou, Vivian Detopoulou, Anastasia Anastasiadou, Christine Kortsalioudaki, Elina Ioannou, Margarita Bartsota, Thodoris Liarigkovinos, Manolis Birbilis, Elina Dimitropoulou, Theodoros Athanasoulis, Pari Christofidou, Lilia Charila, Sofia Tzitzirika and Christos Vassilopoulos for their contribution to the completion of the study.

The authors declare that they have no conflict of interest. The present study was supported in part by grant 17/ D17566 from the Medical Research Council/Biotechnology and Biological Sciences Research Council associate program in human nutrition research and a grant from Friesland Food Hellas. The study sponsor had no role in the design and conduct of the study; the collection, management, analysis and interpretation of the data; the preparation, approval and submission of the manuscript. All authors contributed in writing of the manuscript and interpretation of the results, reviewed its content and approved the final version submitted for publication. Furthermore, Y. M. contributed to the design of the study and supervised data collection; E. R. G. contributed to the design of the study; G. K. carried out the statistical analysis and contributed to data collection; Y. P. P. supervised the laboratory analysis (genetic analysis); V. L. contributed to data collection and laboratory analysis; E. G. and K. K. contributed to data collection, data management and preparation of the database; C. N. M. contributed to laboratory analysis.

\section{References}

1. Caprio S \& Genel M (2005) Confronting the epidemic of childhood obesity. Pediatrics 115, 494-495.

2. Ebbeling CB, Pawlak DB \& Ludwig DS (2002) Childhood obesity: public-health crisis, common sense cure. Lancet 360, 473-482.

3. Lissau I (2004) Overweight and obesity epidemic among children. Answer from European countries. Int J Obes Relat Metab Disord 28, Suppl. 3, S10-S15.

4. Hill JO, Wyatt HR, Reed GW \& Peters JC (2003) Obesity and the environment: where do we go from here? Science 299, $853-855$.

5. Koivisto Hursti UK (1999) Factors influencing children's food choice. Ann Med 31, Suppl. 1, 26-32.

6. Meirhaeghe A, Helbecque N, Cottel D \& Amouyel P (1999) $\beta 2$-Adrenoceptor gene polymorphism, body weight, and physical activity. Lancet 353, 896.

7. Perusse L \& Bouchard C (2000) Gene-diet interactions in obesity. Am J Clin Nutr 72, 1285S-1290S

8. Maes HH, Neale MC \& Eaves LJ (1997) Genetic and environmental factors in relative body weight and human adiposity. Behav Genet 27, 325-351.

9. Snyder EE, Walts B, Perusse L, Chagnon YC, Weisnagel SJ, Rankinen T \& Bouchard C (2004) The human obesity gene map: the 2003 update. Obes Res 12, 369-439.

10. Bernstein KE, Martin BM, Edwards AS \& Bernstein EA (1989) Mouse angiotensin-converting enzyme is a protein composed of two homologous domains. J Biol Chem 264, 11945-11951.

11. Skidgel RA \& Erdos EG (2004) Angiotensin converting enzyme (ACE) and neprilysin hydrolyze neuropeptides: a brief history, the beginning and follow-ups to early studies. Peptides $\mathbf{2 5}$, $521-525$.

12. Engeli S, Gorzelniak K, Kreutz R, Runkel N, Distler A \& Sharma AM (1999) Co-expression of renin-angiotensin 
system genes in human adipose tissue. $J$ Hypertens 17, $555-560$.

13. Jones BH, Standridge MK \& Moustaid N (1997) Angiotensin II increases lipogenesis in 3T3-L1 and human adipose cells. Endocrinology 138, 1512-1519.

14. Strazzullo P, Iacone R, Iacoviello L, et al. (2003) Genetic variation in the renin-angiotensin system and abdominal adiposity in men: the Olivetti Prospective Heart Study. Ann Intern Med 138, $17-23$.

15. Lagou V, Manios Y, Moran CN, Bailey ME, Grammatikaki E, Oikonomou E, Ioannou E, Moschonis G, Wilson RH \& Pitsiladis YP (2007) Developmental changes in adiposity in toddlers and preschoolers in the GENESIS study and associations with the ACE I/D polymorphism. Int J Obes (Lond) 31, $1052-1060$.

16. Moran CN, Vassilopoulos C, Tsiokanos A, Jamurtas AZ, Bailey ME, Wilson RH \& Pitsiladis YP (2005) Effects of interaction between angiotensin I-converting enzyme polymorphisms and lifestyle on adiposity in adolescent Greeks. Obes Res 13, 1499-1504.

17. Manios Y (2006) Design and descriptive results of the "Growth, Exercise and Nutrition Epidemiological Study In preSchoolers": the GENESIS study. BMC Public Health 6, 32.

18. Centers for Disease Control and Prevention \& Division of Public Health Surveillance Sys (2004) Epi Info ${ }^{\text {TM }}$ Database and Statistics Software for Public Health Professionals. Atlanta, GA: CDC.

19. National Center for Health Statistics (2000) CDC Growth Charts. Hyattsville, MD: National Center for Health Statistics.

20. University of Crete (1991) Food Composition Tables (in Greek). http://nutrition.med.uoc.gr/GreekTables

21. Trichopoulou A (2004) Composition Tables of Foods and Greek Dishes. Athens: School of Medicine, Department of Hygiene and Epidemiology.

22. Moreno LA \& Rodriguez G (2007) Dietary risk factors for development of childhood obesity. Curr Opin Clin Nutr Metab Care 10, 336-341.

23. Rodriguez G \& Moreno LA (2006) Is dietary intake able to explain differences in body fatness in children and adolescents? Nutr Metab Cardiovasc Dis 16, 294-301.

24. Gillis LJ, Kennedy LC, Gillis AM \& Bar-Or O (2002) Relationship between juvenile obesity, dietary energy and fat intake and physical activity. Int J Obes Relat Metab Disord 26, 458-463.

25. Berkey CS, Rockett HR, Field AE, Gillman MW, Frazier AL, Camargo CA Jr \& Colditz GA (2000) Activity, dietary intake, and weight changes in a longitudinal study of preadolescent and adolescent boys and girls. Pediatrics 105, E56.

26. Manios Y, Grammatikaki E, Papoutsou S, Liarigkovinos T, Kondaki K \& Moschonis G (2008) Nutrient intakes of toddlers and preschoolers in Greece: the GENESIS study. $J$ Am Diet Assoc 108, 357-361.

27. Guillaume M, Lapidus L \& Lambert A (1998) Obesity and nutrition in children. The Belgian Luxembourg Child Study IV. Eur J Clin Nutr 52, 323-328.

28. McGloin AF, Livingstone MB, Greene LC, Webb SE, Gibson JM, Jebb SA, Cole TJ, Coward WA, Wright A \& Prentice AM (2002) Energy and fat intake in obese and lean children at varying risk of obesity. Int J Obes Relat Metab Disord 26, 200-207.
29. Gazzaniga JM \& Burns TL (1993) Relationship between diet composition and body fatness, with adjustment for resting energy expenditure and physical activity, in preadolescent children. Am J Clin Nutr 58, 21-28.

30. Maffeis C, Pinelli L \& Schutz Y (1996) Fat intake and adiposity in 8 to 11-year-old obese children. Int $J$ Obes Relat Metab Disord 20, 170-174.

31. Maillard G, Charles MA, Lafay L, Thibult N, Vray M, Borys JM, Basdevant A, Eschwege E \& Romon M (2000) Macronutrient energy intake and adiposity in non obese prepubertal children aged 5-11 y (the Fleurbaix Laventie Ville Sante Study). Int J Obes Relat Metab Disord 24, 1608-1617.

32. Maffeis C, Talamini G \& Tato L (1998) Influence of diet, physical activity and parents' obesity on children's adiposity: a fouryear longitudinal study. Int J Obes Relat Metab Disord 22, $758-764$.

33. Bogaert N, Steinbeck KS, Baur LA, Brock K \& Bermingham MA (2003) Food, activity and family-environmental vs biochemical predictors of weight gain in children. Eur J Clin Nutr 57, 1242-1249.

34. Magarey AM, Daniels LA, Boulton TJ \& Cockington RA (2001) Does fat intake predict adiposity in healthy children and adolescents aged 2-15y? A longitudinal analysis. Eur $J$ Clin Nutr 55, 471-481.

35. Atkin LM \& Davies PS (2000) Diet composition and body composition in preschool children. Am J Clin Nutr 72, 15-21.

36. Maffeis C, Provera S, Filippi L, Sidoti G, Schena S, Pinelli L \& Tato L (2000) Distribution of food intake as a risk factor for childhood obesity. Int J Obes Relat Metab Disord 24, $75-80$.

37. Davies PS (1997) Diet composition and body mass index in pre-school children. Eur J Clin Nutr 51, 443-448.

38. Parizkova J \& Rolland-Cachera MF (1997) High proteins early in life as a predisposition for later obesity and further health risks. Nutrition 13, 818-819.

39. Scaglioni S, Agostoni C, Notaris RD, Radaelli G, Radice N, Valenti M, Giovannini M \& Riva E (2000) Early macronutrient intake and overweight at five years of age. Int $J$ Obes Relat Metab Disord 24, 777-781.

40. Rolland-Cachera MF, Deheeger M, Akrout M \& Bellisle F (1995) Influence of macronutrients on adiposity development: a follow up study of nutrition and growth from 10 months to 8 years of age. Int J Obes Relat Metab Disord 19, 573-578.

41. Kim SH, Mauron J, Gleason R \& Wurtman R (1991) Selection of carbohydrate to protein ratio and correlations with weight gain and body fat in rats allowed three dietary choices. Int $J$ Vitam Nutr Res 61, 166-179.

42. Rigat B, Hubert C, Alhenc-Gelas F, Cambien F, Corvol P \& Soubrier F (1990) An insertion/deletion polymorphism in the angiotensin I-converting enzyme gene accounting for half the variance of serum enzyme levels. J Clin Invest 86, 1343-1346.

43. Goossens GH, Blaak EE, Saris WH \& van Baak MA (2004) Angiotensin II-induced effects on adipose and skeletal muscle tissue blood flow and lipolysis in normal-weight and obese subjects. J Clin Endocrinol Metab 89, 2690-2696.

44. Tucker KL (2007) Assessment of usual dietary intake in population studies of gene-diet interaction. Nutr Metab Cardiovasc Dis 17, 74-81. 